\title{
A Review on Smart Campus Concept and Application towards Enhancing Campus Users' Learning Experiences
}

\author{
Faizul Azli Mohd Rahim ${ }^{* *}$, Nurshuhada Zainon ${ }^{1}$, Nur Mardhiyah Aziz ${ }^{1}$, Loo Siaw Chuing ${ }^{1}$ \\ and U.H. Obaidellah ${ }^{2}$
}
${ }^{1}$ Centre for Building, Construction \& Tropical Architecture (BuCTA), Faculty of Built Environment, Universiti Malaya, 50603 Kuala Lumpur, Malaysia
${ }^{2}$ Department of Artificial Intelligence, Faculty of Computer Science \& Information Technology, Universiti Malaya, 50603 Kuala Lumpur, Malaysia.

*Email: azli@um.edu.my

\begin{abstract}
The smart campus is an emerging trend that allows universities to improved services, decision making and campus sustainability. The recent pandemic has directed and amplified the need for a paradigm shift, with predominant virtual teaching, and remote working bursting onto the scene. As an educational institution, understanding campus user's learning experience is vital in the process of assessing and ensuring quality university studies. Therefore, this study provides a review of smart campus concept, application and potential opportunities that emerge in the smart campus towards enhancing campus users' learning experiences. To achieve the purpose of the study, a systematic literature review has been conducted extracted from the Scopus database. Initially, 19 articles were gathered. After the screening process using the inclusion and exclusion criteria, 16 articles were screened and finally, 11 articles were included in the review. This study found that smart campus is an integral concept that needs to be developed and applied in universities. Besides that, several potential opportunities emerging from the smart campus application such as the application of augmented reality and virtual reality in facilitating the learning process, the exploration of daily internet traffic that enables traffic forecasting to improve network service and personalised services. Thus, this study helps to explore the potential fields of employing smart campus especially in the learning process among community campus.
\end{abstract}

Keywords: Augmented reality; Virtual reality; Information Communication Technology; Internet of things; Smart Campus; Smart University

\subsection{INTRODUCTION}

The Industry 4.0 and the COVID-19 pandemic have accelerated the need for the education sector to undergo a digital revolution where digital ways of working are replacing traditional tools and processes. The application of digital tools in the education field increases the quality of the learning process, research development, information gathering, information services and management, in which the tasks can be done systematically and efficiently (Gopal, 2020).

Therefore, the application of digital tools in the learning process could be associated with the concept of digital learning. This concept describes the use of technology as a facilitator of the learning process in which it exposes students to several components of control over time, place, path and pace. 
Besides that, the process of obtaining digital teaching materials for educational activities online or offline via a wired or wireless network can be considered as digital learning (Anttila et al. 2012). The technology has brought so many benefits and provided students with new learning experiences and approaches. According to Panel (2002), among the contents and development of skills that can be understood and adopted by students are such as analytical reasoning, problem-solving, assessment information, and creative thinking.

Eventually, the development of digital learning has diversified to include a new concept called the smart campus. The smart campus has been commonly considered from education and learning perspectives as it helps to improve the learning experiences and gear up towards the Industry 4.0. provides a comprehensive definition of smart campus that includes various aspects described as "a new thinking concept related to the holistic smart campus environment characterized by smart campus ideas such as holistic e-learning, social networking and communication for work collaboration, green sustainability and ICT with smart sensor management systems, protection and prevention, smart building management with automatic security control and supervision, and on-campus governance and reporting

Across the globe, universities are increasingly opting for a smart campus approach. According to Niemtus (2019), the United States is leading the way, with on-campus innovations around energy (University of Texas), transport (University of Michigan) and information (University of Minnesota), updated with real-time data. In the United Kingdom, the University of Glasgow is planning to adopt artificial intelligence (AI) on demand-bus service and data centre powered by renewable energy. Deakin University in Australia has built and implemented a digital assistant with information on assignments, timetables, referencing and other student-related information.

As creating a smart campus is gaining significance worldwide, therefore it is important to the potential opportunities that emerge from the smart campus concept and application, especially when the recent COVID-19 pandemic has alerted the university communities worldwide for the need of digital transformation. The opportunities that exist within the smart campus are believed to enhance the users' experiences especially in the learning process (Ozcan, 2018). Therefore, this paper aims to explore the smart campus concept, applications and potential opportunities that emerge in enhancing users' learning experiences. A comprehensive review and analysis were conducted in terms of means and methods of collecting literature to gain an understanding of the concept, as well as assisting students and educators integrate smart campus concepts into functional applications.

\subsection{METHODOLOGY}

\subsection{Research Design}

A systematic review was developed to explore how the university campus employs the concept of smartness which integrates the use of Information Communication Technology (ICT) and Internet of Things (IoT) to improve the campus users' learning experiences in the campus.

\subsection{Search Strategy}

A systematic literature search was undertaken in the Scopus database using PRISMA flow as presented in Figure 1. The search was set to English language and restricted to papers published between 2015 to 2019, looking into the last five years of this study was conducted. The keywords used were "smart campus", "smart university", "digital learning", and "user learning experience". Through the search operator, the exact-match search tool was also used including "OR", "AND", "*” and "( )". This has yielded 19 articles at the initial stage. After considering the inclusion and exclusion criteria to screen the titles, and/or abstracts, 16 articles remained. The research team then reread these articles to determine their eligibility for the study and found that only 11 articles meet the research objectives. The 
remaining five articles were excluded with reasons that it is outside the scope of study and does not meet the purpose of the study.

\subsection{Inclusion and Exclusion Criteria}

All articles included were journal articles and conference papers published between 2015 and 2019 and written in English. The journal articles and conference papers discussed how the university campus develop the concept of smartness to interact and connect in efficient and reliable ways that were not possible before. The inclusion criteria include IoT, IT application in education, and advantages and disadvantages of IT application in teaching and learning.

\subsection{Data Analysis}

From the retrieved articles that meet all the inclusion criteria, data were arranged using the following headings: author and data, design and data collection and findings/ results (refer to Table 1). Common themes were identified and grouped into several headings using thematic analysis. Transcribed data was assessed to identify the general ideas collected from all the respondents according to themes. The themes were then coded to group similar information, subsequently, the information was tabulated in a table form. Scope of study, the language of the article and non-Scopus publications were excluded from the search.

\subsection{RESULT}

Systematic search has identified sixteen studies, of which 11 studies were used for qualitative synthesis in the final stage. The details for each study are presented in Table 1 which contains the objectives, research methods and findings. 

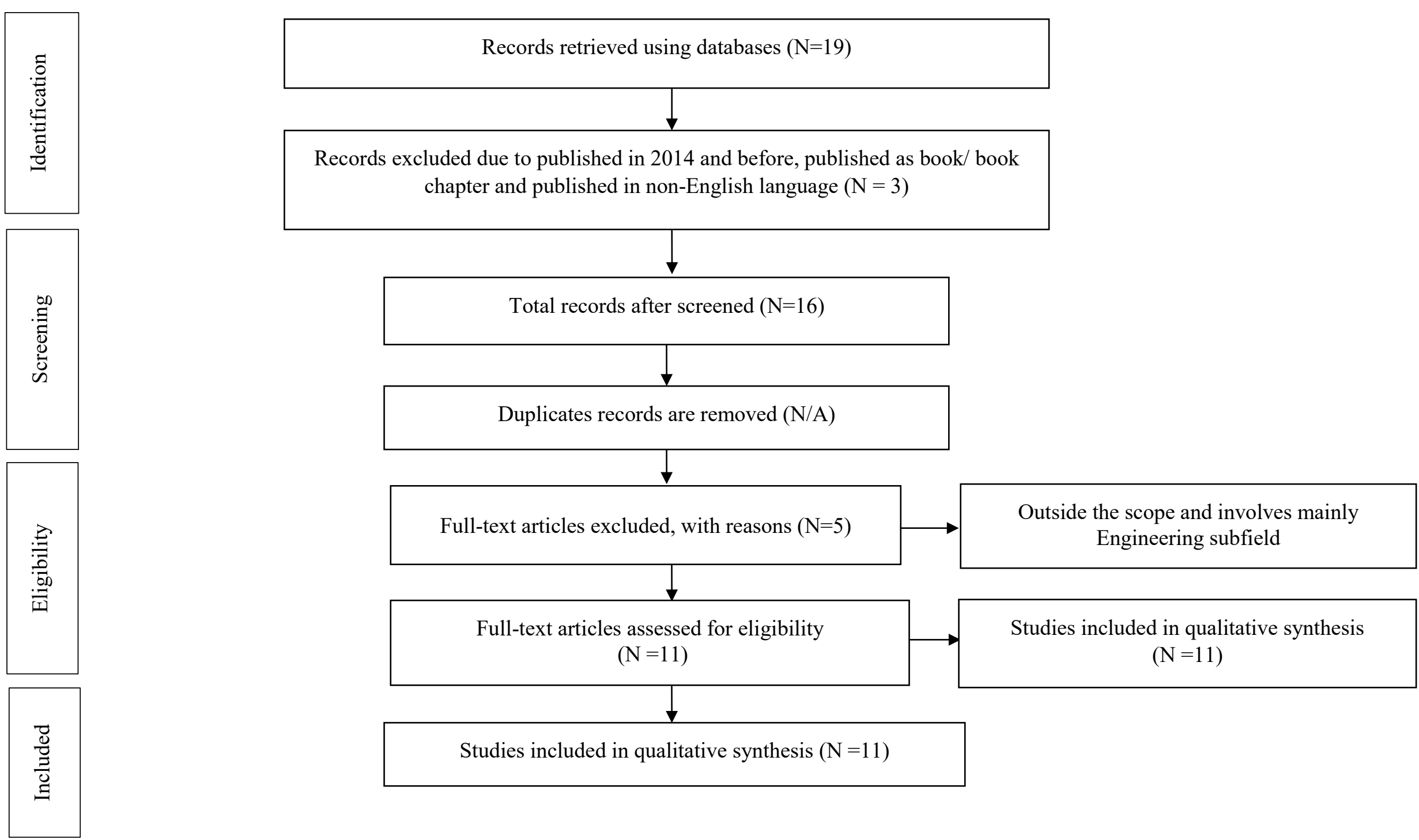

Figure 1: PRISMA Flow Diagram (Moher et al., 2009) 
Table 1: Details of the included studies

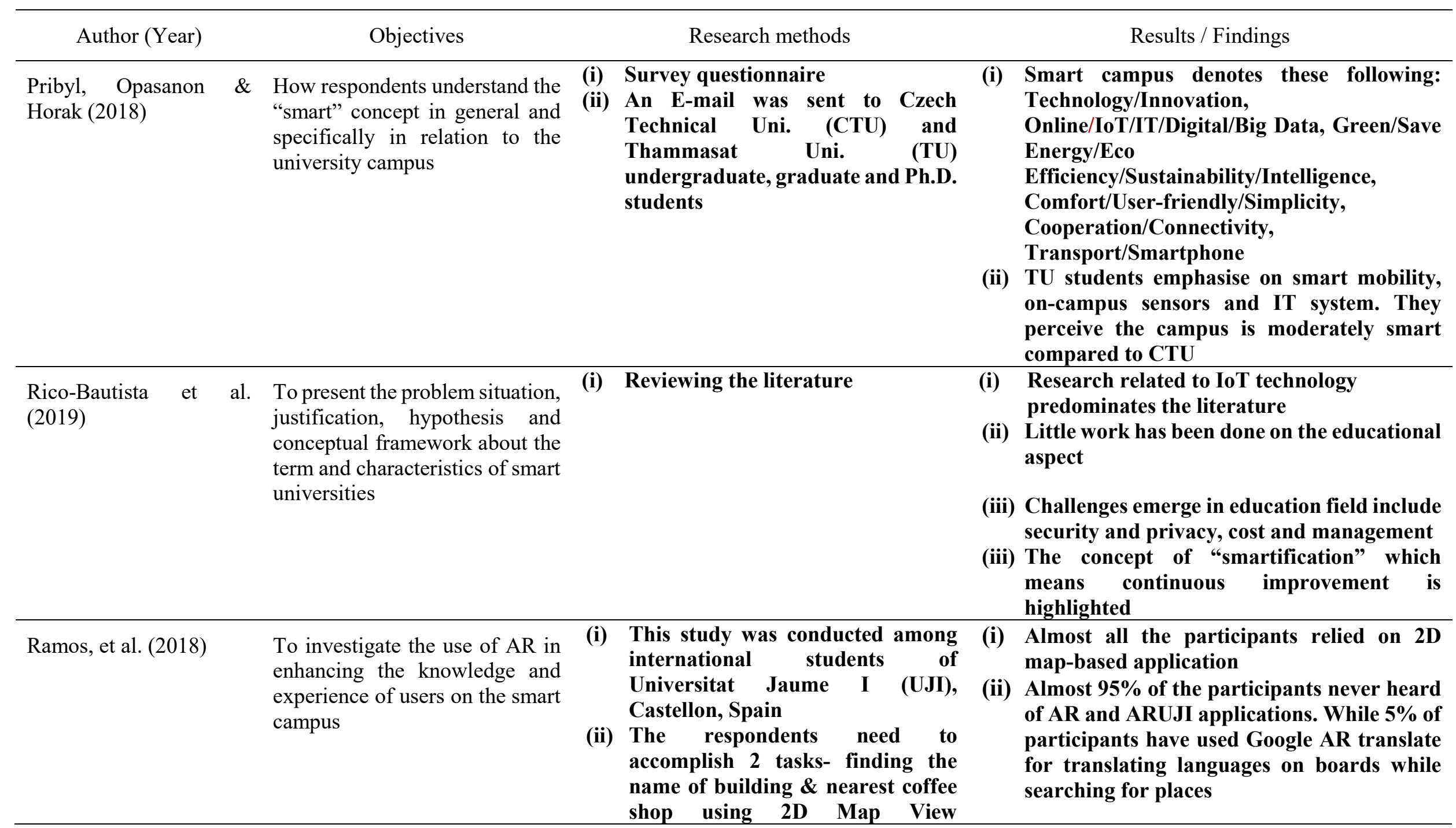


application (Google Maps) and an AR View (ARUJI application) as IV, while the DV are Effectiveness, Efficiency, and Satisfaction.

(iii) The successful completion of two searching tasks represents the Effectiveness of 2D Map \& AR view, while Efficiency was determined by the time it takes to complete a task successfully. The Questionnaire

Variables in the questionnaire: Ease of Use, Clarity of information,

Controllability, Helpfulness, and Fun

Adeyemi et al. (2018) To predict accurately internet data traffic prediction models for computer network planning Satisfaction is determined in the

(iii) AR usages are mostly related to entertainment (Facebook AR Effects, Pokemon Go) and education (the world lens translations through the augmented reality feature in Google Translate)

(iv) Future research includes in-depth interviews and observation to get more statistically and intriguing results because the findings were based on self-reported data.

(v) Focused on international students, however other students also in need of the apps

(i) Predictions of Internet data traffic will help network engineers to improve the Quality of Service (QoS) of computer networks and also ensure efficient utilization of the networks in a smart university campus

(ii) Availability of datasets on Internet data traffic derived from real scenarios will facilitate more empirical research in the field of computer networks and Internet traffic engineering

For each day of the one-year study period, Internet data download traffic and Internet data upload traffic at Covenant University, Nigeria was monitored and properly logged using an opensource software, FreeRADIUS, Radius Manager web application, and Mikrotik Hotspot Manager (iii) Free access to daily Internet data traffic for a period of one year will facilitate the development of empirical prediction models that can be used by Internet Service Providers (ISPs) and Internet subscribers in a smart university campus for effective network planning and traffic forecasting 
(iv) Assist university network administrators to obtain useful information about the traffic peak and non-peak periods.

Yang et al. (2018) To introduce and analyse the current research status of smart campus and the difficulties in integrating various kinds of service data in the smart campus

Comparison of literature review

Universities that implement smart campus:

(i) Swiss Federal Institute of Technology has constructed an Everything Has Online Content (ETHOC) system, which considers the design from information provider interface and user interface to realize the campus information interaction

(ii) Yonsei University Korea, learners use intelligent devices to access the smart campus and construct the smart campus by the means of big data, IoT, cloud service, SNS and other information technology

(iii) To build a smart classroom with low energy use, Brescia University Italy has adopted the Building Energy Model (BEM), a method developed based on Building Information Model (BIM)

(iv) Hiroshima University, Japan uses cloud computation and radio frequency technology- attendance system-can check attendance anytime and anywhere through intelligent terminals and realize the information sharing

(v) The Marist Institute has created a big data analytic platform that analyses curriculum development and academic performance of students based on big data to help students complete the course assignments.

Heneimann \& Uskov To present the outcomes of an (2018) ongoing project aimed at a
Systematic literature review (i) A paradigm shift from traditional education to SMART education

(ii) Approaches to Develop Smart Universities 
systematic literature review and

creative analysis of publications
To propose a scheme that can facilitate the construction of a smart and friendly campus
On-Campus Mobile Apps

(iii) Approaches to Develop Smart Campuses

(iv) Approaches to Develop Smart Classrooms

(v) Approaches to Develop Smart Education or Smart Learning

(vi) Smart University

(vii) Smartness Maturity Model

(i) Proposed schemes: (a) Personalised services, (b) scientific guidance and (c) resource optimisation

(ii) Incorporate interest mining into the smart campus by offering customized services based on context, location, user profile and distance, and other relevant information to facilitate college students.

(iii) The Smart Campus should be able to provide information to the faculty on student affairs.

(iv) Term "campus emotion"- evaluation of the emotional state of most students

(viii) Resource optimisation through mobile apps "OnCampus"

Joaquín et al. (2015) To focus on Smart Mobility by improving one of its key components: positioning
A novel indoor positioning system (IPS) that is combined with an outdoor positioning system and SMART UJI services
2 end-user mobile applications: the SmartUJI APP and the SmartUJI AR.

Smart UJI Apps

(i) Campus map along with relevant info

(ii) The info to display is selected by the user with a menu in categories-transportation, parking, facilities

(iii) Allows users to obtain information about staff members, offices, classrooms, facilities, and buildings simply by entering the required person / building name 
(iv) The apps return a list of matches, with all its useful information, and display that information on the map.

(v) Offers location-based services-seamless indoor/outdoor map-based navigation using Route Calculation-to calculate the best route btw 2 points- if person indoor using IPS, outdoor using GPS

SmartUJI AR

(i) Visualize nearby POI and display in realtime

(ii) The apps have been developed using MetaioSDK-AR API for mobile devices

(iii) With this tool, able to visually locate and filter POI

(iv) Able to calculate the route to any university facilities from current location by jointly using SMARTUJI IPS for indoor and GPS sensor for outdoor location

Adamko (2017) To investigate software systems and related aspects of this evolution to introduce an open architecture for easily extensible services
Data mining technique

(i) Faculty inner portal that is based on Java $E E$ is the outcome from services that they created for Smart campus, involves 3 layers- enterprise layer, service layer and persistence layer.

(ii) Implemented services:

Instructors' office opening hours, Online presence and chat, Nearby events on a map, Sensor data collector, Indoor positioning, Personal calendar as a service

(iii) Initial version-consumer app showing upcoming lectures \& deadlines under events 
Uskov et al., (2016)

To identify a Smart University's

main (1) features, (2)

components, and (3) systems

that go well beyond those in a

traditional university with

predominantly face-to-face

classes and learning activities
Literature review

(i) Important concepts: Smart university, Smart Learning Environment, Smart Education, Smart Campus, Smart Teachers, Smart Learning Community

(ii) Distinctive Features of Smart University: Adaptation, Sensing, Inferring, Selflearning, Anticipation, Self-organisation

(iii) Smart University Distinctive Main Components: Software system, Technology, Hardware, Smart curricula, Student, faculty, Smart pedagogy, Smart classroom

Zhamanov et al. (2017) To review concepts of the Internet of Things, smart campus model and applications
BenefitsIoT IOT campus:

(i) Save cost and time- save energy and water, monitor environmental conditions, such as humidity, pressure, temperature

(ii) Automate maintenance-sensor helps to monitor the condition of the equipment

(iii) Protect the environment- security purposes

(iv) Achieve efficient parking

(v) Student and staff attendance system

(vi) Occupancy detection and tracking: Smart attendance system by using RFID tags

- Smart lab with sensors and actuators for time and resources save

- Smart libraries wIoT IoT element to provide securable books for student's rent

- Flipped classroom as an element of IoT education 
Referring to Table 1, it can be inferred that the majority of the studies discussed the concept of smart in university and campus such as in the studies of Pribyl, Opasanon \& Horak (2018); RicoBautista et al. (2019); Yang et al. (2018); Heneimann \& Uskov (2018); Uskov, et al. (2016). Besides that, the application of Mobile Maps, Virtual Reality (VR) and Augmented Reality (AR) mobile applications have become the focus of interest among researchers such as Ramos et al., (2018) and Joaquín et al. (2015). In addition, the exploration of daily internet data traffic employ in campus settings is crucial in a research study (Adeyemi et al., 2018). Nevertheless, personalised services as introduced by Xin et al. (2016) and Adamko (2017) have also become the research interest to provide more extensible and individualised services among the users.

On the other hand, these researchers employ different kinds of data collection methods in achieving their research purposes. Methods are varied from survey questionnaires (Pribyl, Opasanon \& Horak, 2018 and Ramos et al. 2018), developing mobile applications (Xin et al. 2016; Ramos et al. 2018 and Joaquín et al. 2015), reviewing literature (Rico-Bautista, Medina-Cárdenas, \& Guerrero, 2019; Yang et al. 2018 and Heneimann and Uskov 2018), data exploration (Adeyemi et al., 2018) to data mining technique (Adamko 2017).

\subsection{DISCUSSION}

\subsection{Smart Campus Concept}

The majority of the studies discuss about concept of smart campus and smart university. This topic has been given considerable attention by the researchers as it is the basis of knowledge and understanding of the smart campus concept. Smart campus, also refers to as intelligent campus (icampus), is comprised of holistic e-learning, social networking, communication for work collaboration, green and ICT sustainability, among others (Kwok, 2015). Thus, Kwok (2015) has given a comprehensive definition of smart campus that emerges from several themes such as the approach towards the learning process, the usage of ICT, the elements of smart cities and smart building. The concept of smart campus has also been discussed in the study of Pribyl, Opasanon \& Horak (2018), in which they enquire about this concept among students in two universities (Thailand and Czech Republic) through online survey platform. The students portray different perceptions in which the students in Thailand university perceive smart campus as integral in assisting their daily lives in the campus as compared to Czech Republic university students. The differences in perception could be due to cultural and geographical differences.

On the other hand, the use of technology on the campus is prevalent, moreover with the integration of IoT in the smart campus environment (Rico-Bautista, Medina-Cárdenas, Guerrero 2019). The concept of IoT brings the power of the Internet, data processing and analytics to the real world of physical objects (Valks et al, 2021), as presented in Figure 2. For users, this means interacting with the global information network without the intermediary of a keyboard and screen; many of their everyday objects and appliances can take instructions from that network with minimal human intervention. Majority of the research involves IoT technology, especially in the education field. However, more emphasis is needed on the challenges such as security and privacy, cost, management and reliable internet connection (Shahla et al. 2017). By this, the research introduces the concept of smartification, which involves continuous improvement to imply a paradigm shift or model, aimed at reinforcing the concept of a more open university. If these challenges can be resolved, it can enhance campus community experiences. 


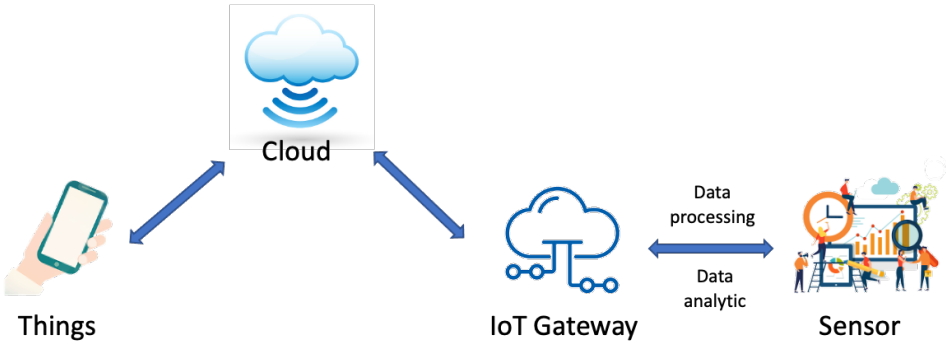

Figure 2: Main components of IoT

\subsection{Opportunities for Utilising Augmented Reality and Virtual Reality in Education to Enhance Campus Users' Learning Experiences}

In addition, the IoT has brought along the technological tools known as Augmented Reality (AR) and Virtual Reality (VR). These technologies have become renowned and desirable nowadays since massive demands towards AR and VR. Both of these tools are used as simulation-based training that can be delivered via portable tablets or conventional flat panel displays. VR implies a complete immersion experience that shuts out the physical world using VR devices such as a headset which users can be transported into several real-world and imagined environments digitally (Daniela, 2020). On the other hand, AR allows users to see the real world but overlays virtual elements by adding digital elements to a live view by using the camera on a smartphone or tablet (Kaplan et al, 2020). It is forecasted that the demands of both tools would even higher in the near future (The App Solutions 2018).

The application of AR and VR is not exceptional in the smart campus environment since these technologies ensure smart mobility among the campus community. As such, AR and VR have been used as navigators inside the campus (Joaquín et al. 2015). The AR and VR technology are rather appealing and stimulating than the 2D map view application (Google map) (Ramos et al. 2018). Since AR and VR have been widely used in various industries like entertainment, tourism, military among others, there is an opportunity to employ AR and VR in the education field to enhance users' experiences on campus.

Since the smart campus entails a holistic e-learning approach, thus AR and VR could be employed to transform learning, teaching and research approaches. Several opportunities could be linked to the usage of AR and VR in the learning process. First, the opportunities to expand teaching possibilities. It is sometimes challenging for lecturers, teachers or instructors to describe and exemplify complicated concepts more practically and easily. Meanwhile, not everyone has the same ability to comprehend the concepts and learning process. Thus, AR and VR education apps provide the solution with an interactive audio-visual interface, basic 3D design, modelling and others to facilitate the learning process (Haymaker \& Fischer 2001; Messner et al. 2002; Messner et al. 2003; Wang et al. 2011;).

Second, providing opportunities for disabled people to education. AR and VR provide and widen the opportunities for students with disabilities or impairment. For example, an application known as Near-Sighted VR Augmented Aid can assist students with visual impairment and Sign Aloud Gloves allow people to communicate using sign language in a VR environment, which later it helps to translate into human speech (The App Solutions 2018).

\subsection{Exploration of Internet Data Traffic Is Crucial in Improving Smart Campus Experiences}

Apart from that, the exploration of internet data traffic is crucial in improving smart campus experience. It can be said that little attention has been given to data exploration although it provides many benefits to the campus users. According to Adeyemi et al. (2018), the quality of computer network services can be improved, while ensuring efficient network usage on smart university campuses. 
Secondly, more empirical research and case studies in computer engineering and internet traffic engineering are possible as the availability of dataset from real scenarios. Thirdly, it facilitates the development of empirical prediction models that can be used by Internet Service Providers (ISPs). This can ensure effective network planning traffic forecasting for future usage. Finally, the administrators could identify the traffic peak and off-peak periods. Thus, the university can properly allocate the network usage, the speed of the internet during the peak period. Besides that, the network administrators and engineers can prepare the contingency plan if the network turns down at any time.

\subsection{Personalised Services for Campus Users in Enhancing Smart Campus Learning Experiences}

On the other hand, with the existence of ICT and IoT, personalised services can be developed to enhance users' experiences on the campus. Personalised services refer to the integration of the application of IoT to optimise the resources, to find common interests and to provide educational guidance (Xin et al. 2016). Customized services based on contextual awareness, location, user profile and distance, and other relevant information can facilitate college students in meeting their needs and utilizing the resources available on campus. For example, the Swiss Institute of Technology has developed the Everything Has Online Content (ETHOC) system, which considers the design of the information provider interface and the user interface to create campus information interactions. Then, Yonsei University of Korea has developed mobile apps known as Open Campus Experience (OCX), where all the cultural, art, and academic activities are notified to students through a mobile calendar. Besides, it also features a shuttle bus location on campus and the occupancy in the cafeteria. The mobile application has facilitated the tasks of students and other faculty members. Thus, more personalised services are needed in the smart campus environment.

\subsection{CONCLUSION}

In summary, the smart campus concept and application are necessary for today's university environment. The role of the smart campus is pervasive as it transforms the learning approaches and processes in a way that never possible before. Nowadays, students need to be exposed to new learning styles that encompass a wide range of technology resources in line with technological advances. The thorough literature review presented in this study identified the concepts, applications and trends in the smart campus. The primary objective of assessing the smart campus concept and application reveals that smart campus concept and application provide various kinds of opportunities such as the application of $\mathrm{VR}$ and $\mathrm{AR}$ in the learning process, the exploration of daily traffic data and personalised services to enhance campus users' experiences.

Future research is recommended to consider applying the smart campus concept and application in the university. This is not only confined to learning features but it should be expanded to other segments that need greater demands by the university's students and the faculty members such as the mobility within the campus and resources management, to provide today's generation of students with extensive use of technology. Besides, various researches can be conducted among the campus users to obtain best practices of smart campus applications.

\section{Acknowledgement}

This project is funded by the research grant, Smart Campus Application towards Sustainable Living: Case of Perdanasiswa Complex and Faculty of Built Environment University Malaya. (RP028A18SUS). 


\subsection{REFERENCE}

1. Adamkó A. (2018). Smart innovation, systems and technologies: building smart university using innovative technology and architecture. New York: Springer International Publishing AG.

2. Adeyemi O, Popoola J, Atayero SI, Afolayan AA, Ariyo DGM, \& Adetiba E. (2018). Exploration of daily internet data traffic generated in a smart university campus. Data in Brief. 20(30): 40-52. doi:10.1016/j.dib.2018.07.039.

3. Anttila M, Valimaki M, Hatonen H, Luukkaala T, Kaila M. (2012). Use of web-based patient education sessions on psychiatric wards. Int J Med Inform. 81(6): 424- 433.

4. Daniela, L. (Ed.). (2020). New Perspectives on Virtual and Augmented Reality: Finding New Ways to Teach in a Transformed Learning Environment. Routledge.

5. Gopal, V. (2020). Digital Education Transformation: A Pedagogical Revolution. i-Manager's Journal of Educational Technology, 17(2), 66.

6. Haymaker J, Fischer M. (2001). Challenges and benefits of 4D modeling on the Walt Disney concert hall project. Stanford (CA): Stanford University.

7. Heneimann C, Uskov VL. (2018). Smart university: literature review and creative analysis. New York (NY): Springer International Publishing.

8. Joaquín Torres-Sospedra, Joan Avariento, David Rambla, Raúl Montoliu, Sven Casteleyn, Mauri Benedito-Bordonau, Michael Gould \& Joaquín Huerta (2015) Enhancing integrated indoor/outdoor mobility in a smart campus, International Journal of Geographical Information Science, 29(11), 1955-1968. doi: 10.1080/13658816.2015.1049541

9. Kaplan, A. D., Cruit, J., Endsley, M., Beers, S. M., Sawyer, B. D., \& Hancock, P. A. (2020). The effects of virtual reality, augmented reality, and mixed reality as training enhancement methods: a meta-analysis. Human Factors. http://doi: 10.1177/0018720820904229.

10. Messner JYS, Baratta A, Riley D. (2002). Cost and schedule reduction of nuclear power plant construction using 4D CAD and immersive display technologies. Information Technology in Civil Engineering International Workshop 2002; Washington (DC); p. 136-144.

11. Messner J, Yerrapathruni S, Baratta A, Whisker V. (2003). Using virtual reality to improve construction engineering education. Proceedings of the 2003 American Society for Engineering Education Annual Conference \& Exposition; Nashville (TN).

12. Moher D, Liberati A, Tetzlaff JJ, Altman DG, The PRISMA Group. (2009). Preferred reporting items for systematic review and meta-analyses: the PRISMA statement. PLoS Med. 6(7): e1000097. https://doi.org/10.1371/journal.pmed.1000097.

13. Niemtus, Z. (2019). Are university campuses turning into mini smart cities?, The Guardian, retrieved from https://www.theguardian.com/education/2019/feb/22/are-university-campusesturning-into-mini-smart-cities

14. Pribyl O,Opasanon S, Horak T. (2018). Student perception of smart campus: a case study of Czech Republic and Thailand. Smart Cities Symposium Prague; May 24-25; Prague, Czech Republic: 2018 Smart City Symposium Prague (SCSP).

15. Panel IL. (2002). Digital transformation: A framework for ICT literacy. Educational Testing 
Service.

16. Ramos F, Trilles S, Torres-Sospedra J, Perales F. (2018). New trends in using augmented reality apps for smart city contexts. ISPRS Int J Geoinf. 7(12), 478-501. doi:10.3390/ijgi7120478

17. Rico-Bautista D, Medina-Cárdenas Y, Guerrero, CD. (2019). Smart university: a review from the educational and technological view of internet of things. In: Rocha Á, Ferrás C, Paredes M. (eds). Switzerland: Springer Cham; p. 427-440.

18. Shahla G, Muhammad A, Shahbaz A, Muhammad Y, Muhammad S, Sheraz M. (2017). A survey on role of internet of things in education. Int. J. Comput. Sci. Netw. 17(5), 159-165.

19. The App Solutions. (2018). Augmented and virtual reality in education. (Accessed 2019 March 1). https://theappsolutions.com/blog/development/ar-vr-in-education/

20. Uskov V.L., Bakken J.P., Pandey A., Singh U., Yalamanchili M., Penumatsa A. (2016) Smart University Taxonomy: Features, Components, Systems. In: Uskov V., Howlett R., Jain L. (eds) Smart Education and e-Learning 2016. Smart Innovation, Systems and Technologies, vol 59. Springer, Cham. https://doi.org/10.1007/978-3-319-39690-3_1

21. Wang X, Dunston PS, Proctor R, Hou L, So J. (2011). Reflections on using a game engine to develop a virtual training system for construction excavator operators. Proceedings of the 28th International Symposium on Automation and Robotics in Construction (ISARC 2011); Seoul; p. $631-636$

22. Valks, B., Arkesteijn, M. H., Koutamanis, A., \& den Heijer, A. C. (2021). Towards a smart campus: supporting campus decisions with Internet of Things applications. Building Research \& Information, 49(1), 1-20.

23. Xin D, Xiangjien K, Fulin Z, Zhen C, Jialiang K. (2016). OnCampus: a mobile platform towards a smart campus. SPRINGERPLUS. 5(974) 1-9. doi: 10.1186/s40064-016-2608-4

24. Yang, AM, Li SS, Ren CH, Liu HX, Han Y, Liu L. (2018). Situational awareness system in the smart campus. IEEE Access, 6, 63976-63986. doi:10.1109/access.2018.2877428.

25. Zhamanov A, Zhulduz S, Rassim S, Zhazira K. (2017). IoT smart campus review and implementation of IoT applications into education process university. $13^{\text {th }}$ International Conference on Electronic, Computer and Computation (ICECCO); November 28-29; Abuja, Nigeria. IEEE: Piscataway (NJ). p. 1-4. 